\title{
Human-Induced Changes in the Hydrology of the Western United States
}

Tim P. Barnett, ${ }^{1 *}$ David W. Pierce, ${ }^{1}$ Hugo G. Hidalgo, ${ }^{1}$ Celine Bonfils, ${ }^{2}$ Benjamin D. Santer, ${ }^{2}$ Tapash Das, ${ }^{1}$ Govindasamy Bala, ${ }^{2}$ Andrew W. Wood, ${ }^{3}$ Toru Nozawa, ${ }^{4}$ Arthur A. Mirin, ${ }^{2}$ Daniel R. Cayan, ${ }^{1}$ Michael D. Dettinger ${ }^{1}$

${ }^{1}$ Scripps Institution of Oceanography, University of California, San Diego, La Jolla, CA 92093, USA. ${ }^{2}$ Lawrence Livermore National Laboratory, Livermore, CA 94550, USA. ${ }^{3}$ Land Surface Hydrology Research Group, Civil and Environmental Engineering, University of Washington, Seattle, WA 98195, USA. ${ }^{4}$ National Institute for Environmental Studies, 16-2, Onogawa, Tsukuba, Ibaraki 305-8506, Japan.

*To whom correspondence should be addressed. E-mail: tbarnett-ul@ucsd.edu

Observations have shown the hydrological cycle of the western U.S. changed significantly over the last half of the twentieth century. Here we present a regional, multivariable climate-change detection and attribution study, using a high-resolution hydrologic model forced by global climate models, focusing on the changes that have already affected this primarily arid region with a large and growing population. The results show up to $60 \%$ of the climate related trends of river flow, winter air temperature and snow pack between 1950-1999 are human-induced. These results are robust to perturbation of study variates and methods. They portend, in conjunction with previous work, a coming crisis in water supply for the western United States.

Water is perhaps the most precious natural commodity in the western United States. Numerous studies indicate the hydrology of this region is changing in ways that will negatively impact the region (1-3). Between 1950 and 1999 there was a shift in the character of mountain precipitation, with more winter precipitation falling as rain instead of snow $(2,4,5)$, earlier snow melt $(4,6)$, and associated changes in river flow (7-10). In the latter case, the river flow experiences relative increases in the spring and relative decreases in the summer months. These effects go along with a warming over most of the region that has exacerbated these drier summer conditions $(5,8,11)$.

The west naturally undergoes multi-decadal fluctuations between wet and dry periods (12). If drying from natural climate variability is the cause of the current changes, a subsequent wet period will likely restore the hydrological cycle to its former state. But global and regional climate models forced by anthropogenic pollutants suggest human influences could have caused the shifts in hydrology $(2,13-$ 15). If so, these changes are highly likely to accelerate, making modifications to the water infrastructure of the western U.S. a virtual necessity.

In this paper, we demonstrate statistically that the majority of the observed low frequency changes in the hydrological cycle (river flow, temperature, and snow pack) over the western U.S. from 1950-1999 are due to human-caused climate changes from greenhouse gases and aerosols. This result is obtained by evaluating a combination of globalclimate and regional-hydrologic models, and sophisticated data analysis. We use a multivariable detection and attribution (D\&A) methodology (16-18) to show the simultaneous hydro climatic changes observed already differ significantly in length and strength from trends expected due to natural variability (detection), and differ in the specific ways expected of human-induced effects (attribution). Focusing on the hydrological cycle allows us to assess the origins of the most relevant climate-change impacts in this water-limited region.

We investigate simultaneous changes from 1950-1999 (19) in snow pack (snow water equivalent or SWE), the timing of runoff of the major western rivers, and average January through March daily minimum temperature (JFM T $\mathrm{T}_{\min }$ ) in the mountainous regions of the western U.S. (20). These three variates arguably are among the most important metrics of the western hydrological cycle. By using the multivariable approach we obtain greater signal to noise ratio than from univariate D\&A alone (see below).

The SWE data are normalized by October-March precipitation $(\mathrm{P})$ to reduce variability from heavy or light precipitation years. Observed SWE/P and temperature were averaged over each of nine western mountainous regions (Fig. 1) to reduce small spatial scale weather noise. The river flow variate is the center of timing (CT), the day of the year one half of the total water year flow has occurred, computed from naturalized flow in the Columbia, Colorado and Sacramento/San Joaquin rivers. CT tends to decrease with warming due to earlier spring melting.

Selected observations from these regions/variables are displayed in Fig. 2, showing the trends noted above, along with substantial regional differences and "weather noise." $\mathrm{SWE} / \mathrm{P}$ trends in the nine regions vary from -2.4 to $-7.9 \%$ per decade, except in the southern Sierra Nevada where the trend is slightly positive. The JFM $\mathrm{T}_{\min }$ trends are all positive and range from $0.28-0.43^{\circ} \mathrm{C} /$ decade, while the river $\mathrm{CT}$ arrives between 0.3 to 1.7 days/decade earlier. The challenge in D\&A analysis is to determine whether a specific, predetermined signal representing the response to external forcing is present in these observations.

We compared the observations with results from a regional hydrologic model forced by global climate model runs. One of the global models, the Parallel Climate Model (PCM) (21), has been used previously in hydrological studies in the western U.S. (22) and realistically portrays important features of observed climate and the amplitude of natural internal variability. The second climate model, the anthropogenically forced medium resolution MIROC (23-25), was selected from the current IPCC AR4 set of global runs (26) because it 
had available many $20^{\text {th }}$ century ensemble members with daily data, and because of its high degree of realism in representing the Pacific Decadal Oscillation (PDO). We used the anthropogenically forced versions of these models to obtain an estimate the expected signal not confounded by other forcing mechanisms. The models provided multiple realizations (10 for MIROC, and 4 for PCM) of the historical response of the climate system to anthropogenic forcing. The daily output from these coarse horizontal-resolution model results was downscaled to a $1 / 8^{\circ} \times 1 / 8^{\circ}$ latitude/longitude grid by two different statistical methods [Bias Correction and Spatial Disaggregation, BCSD (27) and Constructed Analogues, CA (28)]. The downscaled temperature and precipitation data were supplied as input to the Variable Infiltration Capacity, (VIC) hydrological model, (15, 27, 29) to obtain river flow and SWE/P.

We used the downscaled model results to estimate an anthropogenic "fingerprint" for the PCM and MIROC models (30). The fingerprint describes the joint variability of SWE/P, JFM $\mathrm{T}_{\text {min }}$, and river flow (Fig. 3) (20). The model fingerprints are very similar in spite of the different external forcings used $(20,26)$. The results show that warmer temperatures accompany decreases in SWE/P and decreases in CT of major western river systems. The sign of each variable is a monopole, indicating a coherent regional-scale signal over the western U.S.

The temporal component of the fingerprint (not shown) is well-represented by a simple trend. This implies the fingerprint primarily captures the spatial expression of longterm changes, and not shorter-period climate modes (such as ENSO or the PDO).

The signal strength is calculated as the least-squares linear trend of the projection of a data set (model or observations) onto the fingerprint (see supplemental information for details). Fig. 4 (upper) shows the ensemble mean signals for our various model runs and the observations (20). The observations show a positive signal indistinguishable from the PCM and MIROC anthropogenically-forced runs. These signals exclude zero at the $95 \%$ confidence interval, thus achieving “detection”.

We used 1600 years of downscaled control run data from two different global models (20) to estimate the probability that the observed signal could be due to natural, internal variability (Fig. 4, lower panel). The observed signal falls outside the range expected from natural variability with high confidence ( $p<0.01)$. In separate analyses for both PCM and MIROC, the likelihood that the model signal arises from natural internal variability is between 0.01 and 0.001 (20). The different downscaling methods have little impact on these results. We conclude natural internal climate variability alone cannot explain either the observed or simulated changes in SWE/P, JFM $\mathrm{T}_{\min }$, and CT in response to anthropogenic forcing.

PCM simulations forced solely by the combined impacts of observed solar variability and volcanic activity (Sol/Vol, Fig. 4) show a signal with sign opposite to that observed. We conclude solar and volcanic forcing also fail to explain the observed hydrological changes.

Might anthropogenically-induced precipitation changes account for our results? This is unlikely since our variables are chosen to minimize sensitivity to precipitation fluctuations. However, previous work has identified an anthropogenic effect on global-scale changes in precipitation (31). We conducted a univariate D\&A analysis on precipitation, comparing the fingerprint obtained from the anthropogenic runs to the control runs and observations. The results (Fig. 4, lower) show that the observed changes in precipitation over the nine western U.S. mountain regions are indistinguishable from natural variability. We found the same for model precipitation (not shown). We conclude that while precipitation may be affected by anthropogenic forcing on larger scales or in other regions, or in this region in the future, it cannot explain the strong changes in western U.S. hydrology from 1950-1999.

Finally, the observations are consistent with the anthropogenic model runs. The observed signal is stronger than found in either model, but the differences are not statistically significant. The ensemble mean signal strength from PCM is $60 \%$ of the observed signal strength, i.e., PCM estimates three-fifths of the projected trend can be ascribed to human effects. The two downscaling methods give somewhat different signal strengths (Fig. 4), but the attribution holds no matter which is chosen. We conclude that application of a rigorous, multivariable D\&A methodology shows a detectable and attributable signature of human effects on western hydrology.

We examined the time evolution of signal and noise by projecting the observations (signal) and control run data (noise) onto the multivariable fingerprint, then fitting linear trends of increasing length $L$ to the resulting projected time series. This enables us to calculate a signal-to-noise $(\mathrm{S} / \mathrm{N})$ ratio as a function of $L$ (from 10 to 50 years) Figure 5 shows the $\mathrm{S} / \mathrm{N}$ ratio rises above the $5 \%$ significance threshold no later than 1986. This result is robust to uncertainties in the model fingerprint, model-based noise estimates, and statistical downscaling method (20). We also repeated the D\&A analysis without areal weighting, and found it made no difference to our conclusions.

The variables examined here co-vary in a physically and internally-consistent way: an increase in minimum temperature is associated with less SWE/P and earlier runoff. Quantitatively, we also compared the S/N obtained from separate analyses of each variable with that obtained for the full multivariable problem (20). For fixed choices of fingerprint, noise, and downscaling (32), the $\mathrm{S} / \mathrm{N}$ from the separate SWE/P, JFM $\mathrm{T}_{\min }$ and CT analyses were 2.90, 2.95 and 1.85, respectively, all significant at about the 0.05 level or above. The multivariable analysis had a $\mathrm{S} / \mathrm{N}$ of 3.62, and so has quantitative value as well as providing a test of whether SWE/P, JFM T $\mathrm{T}_{\min }$, and CT co-vary in a physically consistent way.

In summary, our results are robust with respect to uncertainties in model estimates of anthropogenic climate fingerprints and natural variability, downscaling method, and the choice of univariate or multivariate D\&A analysis. Estimates of natural variability used for significance testing agree well with those derived from paleo proxies (20). The analyses show with high confidence that the majority of the detrimental changes already seen in western U.S. hydrology are caused by human-induced effects. PCM, which has the most realistic signal strength, shows human effects account for $60 \%$ of the observed 1950-99 trend in signal strength. MIROC accounts for 35\% of the trend. Based on Fig. 4 
(upper) and the discussion of MIROC in the supporting material, the PCM number seems more reliable.

Our results are not good news for those living in the western United States. The scenario for how western hydrology will continue to change has already been published using one of the models employed here [PCM (2)] as well as in other recent studies of western US hydrology [e.g., (15)]. It foretells of water shortages, lack of storage capability to meet seasonally changing river flow, transfers of water from agriculture to urban uses and other critical impacts. Since PCM performs so well in replicating the complex signals of the last half of the $20^{\text {th }}$ century, we have every reason to believe its projections and to act on them in the immediate future.

\section{References and Notes}

1. P. Gleick, Water Resour. Res. 23, 1049 (1987).

2. ACPI, The Accelerated Climate Prediction Initiative, Clim. Change 62 (2004).

3. B. Udall, G. Bates, Intermountain West Climate Summary, Western Water Assessment, January 2007 (available from University of Colorado).

4. A. F. Hamlet, P. W. Mote, M. P. Clark, D. P. Lettenmaier, J. Clim. 18, 4545 (2005).

5. N. Knowles, M. D. Dettinger, D. R. Cayan, J. Clim. 19, 4545 (2006).

6. P. W. Mote, A. F. Hamlet, M. P. Clark, D. P. Lettenmaier, Bull. Am. Meteorol. Soc. 86, 39 (2005).

7. M. D. Dettinger, D. R. Cayan, J. Clim. 8, 606 (1995).

8. D. R. Cayan, S. Kammerdiener, M. D. Dettinger, J. Caprio, D. Peterson, Bull. Am. Meteorol. Soc. 82, 399 (2001).

9. I. T. Stewart, D. R. Cayan, M. D. Dettinger, J. Clim. 18, 1136 (2005).

10. S. K. Regonda, B. Rajagopalan, M. Clark, J. Pitlick, J. Clim. 18, 372 (2005).

11. P. Y. Groisman et al., J. Hydrometeorol. 5, 64 (2003).

12. Colorado River Basin Water Management: Evaluating and Adjusting to Hydroclimatic Variability (National Academy of Sciences, Washington, DC, 2007).

13. P. C. D. Milly, K. A. Dunne, A. V. Vecchia, Nature 438, 347 (2005).

14. R. Seager et al., Science 316, 1181 (2007); published online 4 April 2007 (10.1126/science.1139601).

15. N. Christiansen, D. Lettenmaier, Hydrol. Earth Syst. Sci. Discuss. 3, 1 (2006).

16. T. P. Barnett, M. Schlesinger, J. Geophys. Res. 92, 14772 (1987).

17. B. D. Santer et al., Clim. Dyn. 12, 77 (1995).

18. R. Schnur, K. I. Hasselmann, Clim. Dyn. 24, 45 (2005).

19. Note this period excludes the large scale changes in runoff, precipitation and water storage that has occurred in the southwest, especially the Colorado River drainage, since 2000. We do not claim that the large changes since 2000 are necessarily the result of human-induced warming.

20. See supporting material on Science Online.

21. W. Washington et al., Clim. Dyn. 16, 755 (2000).

22. T. P. Barnett et al., Clim. Change 62, 1 (2004).

23. K-1 Model Developers, K-1 Coupled Model (MIROC) Description (K-1 Technical Report 1), H. Hasumi, S. Emori, Eds. (Center for Climate System Research, University of Tokyo, 2004).

24. T. Nozawa et al., Geophys. Res. Lett. 32, L20719 (2005).
25. T. Nozawa et al., MIROC, CGER's Supercomputer Monograph Report 12 (Center for Global Environmental Research, National Institute for Environmental Studies, Tsukuba, Japan, 2007).

26. B. D. Santer et al., Proc. Natl. Acad. Sci. U.S.A. 104, 15248 (2007).

27. A. Wood et al., Clim. Dyn. 16, 755 (2004).

28. E. P. Maurer, H. G. Hidalgo, Hydrol. Earth Syst. Sci. Discuss. 4, 3413 (2007).

29. X. Liang, D. Lettermaier, A. Wood., S. Burges, J. Geophys. Res. 99, 14415 (1994).

30. T. P. Barnett et al., Science 309, 284 (2005); published online 2 June 2005 (10.1126/science.1112418).

31. X. Zhang et al., Nature 448, 461 (2007).

32. The choices were CCSM3-FV noise for significance testing, PCM fingerprint, and statistical downscaling with the CA method. In the multivariable case, PCM noise was used for normalization.

33. This work was supported by the Lawrence Livermore National Laboratory through an LDRD grant to the Scripps Institution of Oceanography (SIO) via the San Diego Super Computer Center (SDSC) for the LUCSiD project. The MIROC data was generously supplied by the National Institute for Environmental Studies Onogawa, Tsukuba, Ibaraki, JAPAN. The PCM simulation had previously been made available to SIO by the National Center for Atmospheric Research for the ACPI project. This work was also partially supported by Dept of Energy and NOAA through the International Detection and Attribution Group. The LLNL participants were supported by DOE-W-7405-ENG-48 to the Program of Climate Model Diagnoses and Intercomparison (PCMDI). The USGS and SIO provided partial salary support DC and $\mathrm{MD}$ at SIO; the California Energy Commission provided partial salary support for DP and $\mathrm{HH}$ at SIO.

\section{Supporting Online Material}

www.sciencemag.org/cgi/content/full/1152538/DC1

SOM Text

Figs. S1 to S3

References

2 November 2007; accepted 23 January 2008

Published online 31 January 2008; 10.1126/science.1152538

Include this information when citing this paper.

Fig. 1. Location map showing averaging regions over which SWE/P and JFM T $\mathrm{T}_{\min }$ were determined. The hatching shows the approximate outline of the three main drainage basins used in this study.

Fig. 2. Observed time series of selected variables (expressed as unit normal deviates) used in the multi variate detection and attribution analysis. Taken in isolation, seven of nine SWE/P, seven of nine JFM $\mathrm{T}_{\text {min }}$, and one of the three river flow variables have statistically significant trends.

Fig. 3. Fingerprints from the multivariate analysis of PCM and MIROC.

Fig. 4. Ensemble average signal strength (upper, standard deviations of the fingerprint's principal component per decade) and percentile rank of ensemble mean signal strength for the indicated model runs with respect to the combined (CCSM3-FV and PCM) control run (lower). Percentile values calculated by Monte Carlo resampling of the control run 
taking into account $\mathrm{N}$, the varying number of ensemble members. PCM (BCSD) and PCM (CA): PCM runs with anthropogenic forcing, with two different downscaling methods as described in the text $(\mathrm{N}=4)$. MIROC: MIROC runs with anthropogenic forcing $(\mathrm{N}=10)$. Sol/Vol: PCM runs with only solar and volcanic forcing included $(\mathrm{N}=2)$. The cross shows the signal strength obtained from the observations $(\mathrm{N}=1)$. For comparison purposes, also shown is the observed signal strength from a separate analysis of precipitation changes over the nine mountain regions (diamond). Values outside the hatched and crosshatched regions are significant at the 0.01 and 0.05 level, respectively.

Fig. 5. Time dependent $\mathrm{S} / \mathrm{N}$ estimates for two different estimates of natural variability. The $\mathrm{x}$-axis is the last year of L-length linear trend in the signal estimate. 
$\begin{array}{lllll}236^{\circ} & 240^{\circ} & 244^{\circ} & 248^{\circ} & 252^{\circ}\end{array}$

$48^{\circ}$

$44^{\circ}$

$36^{\circ}$

Snow Courses:

$32^{\circ}$

$\checkmark$ OR Cascades

ON. Rockies

WA Cascades
S. Sierras Colo. Rockies

$\nabla N$. Sierras Wasatch

Blue Mtns Great Basin

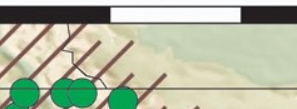

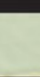
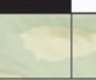

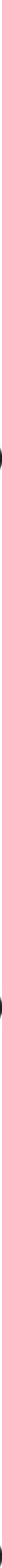



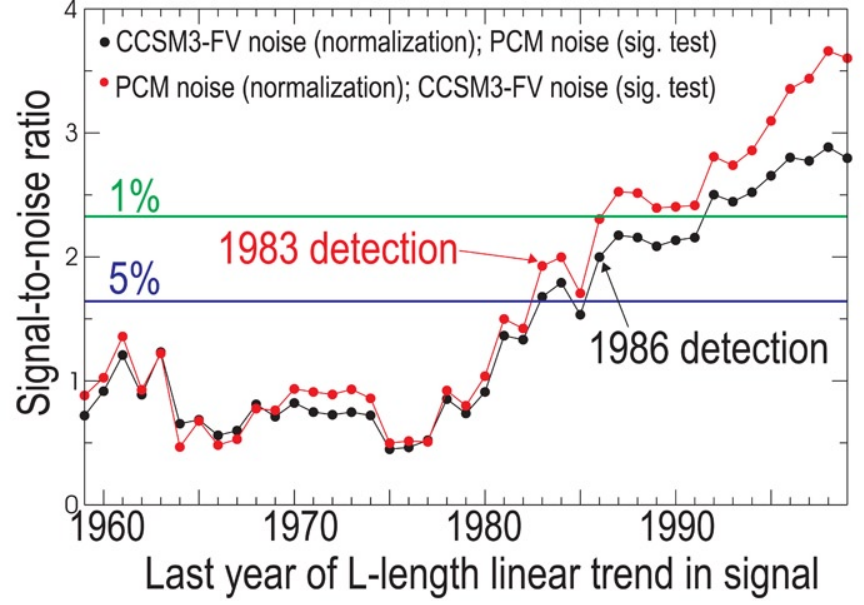

